\title{
Study of adverse drug reactions among tuberculosis patients in a tertiary care hospital: a retrospective observational study
}

\author{
Sahana M. Mogali, Jagadishchandra S. Ratnakar*, Basavaraj C. Kotinatot
}

Department of Pharmacology, Belagavi Institute of Medical Sciences, Belagavi, Karnataka, India

Received: 09 February 2020

Revised: 15 March 2020

Accepted: 18 March 2020

*Correspondence:

Dr. Jagadishchandra S Ratnakar,

Email: dr.jaggusarkar@gmail.com

Copyright: $@$ the author(s), publisher and licensee Medip Academy. This is an open-access article distributed under the terms of the Creative Commons Attribution Non-Commercial License, which permits unrestricted non-commercial use, distribution, and reproduction in any medium, provided the original work is properly cited.

\begin{abstract}
Background: The aims of the study was to study adverse drug reactions (ADRs) among tuberculosis (TB) patients in a tertiary care hospital and to determine causality, severity and outcome of ADRs.

Methods: A retrospective observational study was conducted in a tertiary care hospital over a period of 6 months. Data was collected from records of TB patients in RNTCP centre of a tertiary care hospital regarding information of patients, drugs used, ADRs. It was evaluated using appropriate scales. Simple descriptive statistics was used for analysis.

Results: Out of 37 patients who experienced ADRs, $22(59.45 \%)$ were male and 15 (40.54\%) were female. Majority of patients were in the age group of 36 to 45 years (37.83\%). $36(97.3 \%)$ patients were diagnosed with pulmonary TB and $1(2.7 \%)$ patient had extra pulmonary TB. Among 37 ADRs gastrointestinal (GI) reactions were most common 11 $(29.72 \%)$ followed by musculoskeletal $9(24.32 \%)$. Causality assessment showed $19(51.35 \%)$ as probable and 18 $(48.65 \%)$ ADRs as possible, Severity assessment was $24(64.8 \%)$ reactions were in mild, $10(27.02 \%)$ in moderate and $3(8.1 \%)$ in severe grades. Outcome assessment was $26(70.3 \%)$ patients were recovering from reactions, 9 $(24.32 \%)$ had recovered and $2(5.4 \%)$ did not recover at the time of reporting.

Conclusions: Proper monitoring of ADRs helps in reducing patient's burden of repeated hospital visits and expense occurring due to admissions. This can be prevented by educating patients about early reporting of ADRs.
\end{abstract}

Keywords: ADRs, ATT, Musculoskeletal, Tuberculosis

\section{INTRODUCTION}

Tuberculosis is one of the leading causes of morbidity and mortality worldwide and remains as major public health problem in developing countries. ${ }^{1}$ According to WHO Global TB Report 2019, 10 million people fell ill with TB in 2018 and India accounted for $27 \%$ cases of the total.

Treatment for tuberculosis is not only important for an individual health but also for a public health. ${ }^{2}$ Because of long duration of therapy, there is risk of non-adherence to treatment which leads to prolonged suffering, drug resistance, relapse and death. ${ }^{3}$

Adverse drug reaction is defined as 'any noxious change which is suspected to be due to drug, occurs at doses normally used in man, requires treatment or decrease in dose or indicates caution in the future use of the same drug'. ${ }^{4}$ ADRs cause increased expense to the patients because of additional visits to hospital, laboratory tests, and prolonged hospitalizations. 
Pharmacovigilance activities help in collecting the necessary information regarding safety and effectiveness of drugs and also to prevent and manage ADRs. ${ }^{5}$

Table 1: Important ADRs of antitubercular therapy (ATT). ${ }^{4,6}$

\begin{tabular}{|l|l|}
\hline Peripheral neuritis and hepatitis are & $\begin{array}{l}\text { Penost common ADRs. Others } \\
\text { the monid } \\
\text { include rash, lethargy, anaemia, } \\
\text { acne, drug induced lupus } \\
\text { erythematosus, seizures, and } \\
\text { psychiatric symptoms. }\end{array}$ \\
\hline Rifampicin & $\begin{array}{l}\text { Hepatitis is major ADR. } \\
\text { Gastrointestinal and cutaneous } \\
\text { reactions, flu like symptoms, orange } \\
\text { red colour urine and secretions. }\end{array}$ \\
\hline Pyrazinamide & $\begin{array}{l}\text { Hyperuricemia and joint pain are } \\
\text { important. }\end{array}$ \\
\hline Ethambutol & $\begin{array}{l}\text { Retrobulbar optic neuritis; loss of } \\
\text { ability to see green is main. }\end{array}$ \\
\hline Streptomycin & $\begin{array}{l}\text { Ototoxicity and renal toxicity are most } \\
\text { common. Vestibular dysfunction } \\
\text { includes loss of balance, vertigo, and } \\
\text { tinnitus. }\end{array}$ \\
\hline
\end{tabular}

Drug-related side effects can be minor or major. Those patients who have minor side effects should be encouraged to continue the treatment with symptomatic measures such as antacids, antihistamines, antiemetics or analgesics. But if major side effects occur, the offending drug, if identifiable can be stopped. ${ }^{7}$ Further management depends on the nature of side effects and if needed regimen can be changed depending on tolerability of patients.

\section{METHODS}

It is a retrospective observational study conducted in Revised National Tuberculosis Patients Control Programme (RNTCP) centre over a period of one year from January 2018 to December 2018 at Belagavi Institute of Medical Sciences, Belagavi, a tertiary care hospital. The data was collected from patients' record regarding their demographic details, type of ATT regimen, concomitant drugs used, comorbidities and about ADRs. The study was approved by institutional ethics committee.

\section{Inclusion criteria}

All records of patients who were on ATT with suspected ADRs. Both category I and II patients, and all patients above 18 years age irrespective of sex.

\section{Exclusion criteria}

Patients with acute viral hepatitis, chronic hepatitis and cirrhosis, pregnant and lactating women, and patient records without proper documentation
Data was evaluated for causality, severity and outcome using appropriate scales. Analysis was carried out with simple descriptive statistics like percentage using SPSS 19.0 (IBM Corp., NY, USA).

Causality was assessed based on criteria of WHOUppsala Monitoring Centre which classifies into six categories: certain, probable/likely, possible, unlikely, conditional/unclassified, unassessable/unclassifiable. ${ }^{8}$ Severity of ADRs was determined by using modified Hartwig criteria. ${ }^{9}$

Outcome of reactions were categorized as recovered, recovering, not recovered, recovered with sequelae, fatal or unknown as per Central Drug Standard Control Organization (CDSCO) suspected ADR reporting form.

\section{RESULTS}

A total of 60 ADRs were reviewed, of which 37 patients who met the inclusion criteria were included in the study. Among 37 patients who experienced ADRs, 22 (59.45\%) were male and $15(40.54 \%)$ were female. Majority of patients were in the age group of 36 to 45 years $(37.83 \%)$ as shown in Table 2 .

Table 2: Age wise distribution of ADRs.

\begin{tabular}{|l|l|}
\hline Age group (years) & Number of ADRs (\%) \\
\hline $\mathbf{1 8 - 2 5}$ & $2(5.4)$ \\
\hline $\mathbf{2 6 - 3 5}$ & $6(16.21)$ \\
\hline $\mathbf{3 6 - 4 5}$ & $14(37.83)$ \\
\hline $\mathbf{4 6 - 5 5}$ & $12(32.43)$ \\
\hline $\mathbf{5 6 - 6 5}$ & $5(13.5)$ \\
\hline
\end{tabular}

$36(97.3 \%)$ patients were diagnosed with pulmonary TB and $1(2.7 \%)$ patient had extra pulmonary TB. Out of 37 patients $11(29.72 \%)$ patients were on MDR-TB regimen. $32(86.5 \%)$ patients were on daily regimen ATT and 5 $(13.5 \%)$ patients were on twice per week ATT.

Comorbidities associated with TB was seen in 14 $(37.83 \%)$ patients. Among them 7(18.91\%) had hypertension, 3 had diabetes mellitus and 4 were HIV positive. Of all ADRs reported, gastrointestinal (GI) reactions were the most common $11(29.72 \%)$ followed by musculoskeletal $9(24.32 \%)$. Central and peripheral nervous system reactions were next more frequent 5 (13.5\%) each. Cutaneous 4(10.8\%), hepatobiliary 1 $(2.7 \%)$ and other ADRs like ototoxicity 1 (2.7\%) and decreased vision $1(2.7 \%)$ were also reported as shown in Figure 1.

Maximum number of ADRs was caused by Rifampicin 21 $(56.75 \%)$, followed by pyrazinamide $9(24.32 \%)$ and isoniazid $4(10.8 \%)$ as shown in Table 3.

Causality assessment showed $19(51.35 \%)$ as probable and $18(48.65 \%)$ ADRs as possible, when severity assessment was done $24(64.8 \%)$ reactions were in mild, 
$10(27.02 \%)$ in moderate and $3(8.1 \%)$ in severe grades. Outcome assessment was $26(70.3 \%)$ patients were recovering from reactions, $9(24.32 \%)$ had recovered and $2(5.4 \%)$ did not recover at the time of reporting ADR. 27 $(72.97 \%)$ out of total 37 patients received symptomatic treatment for ADRs.

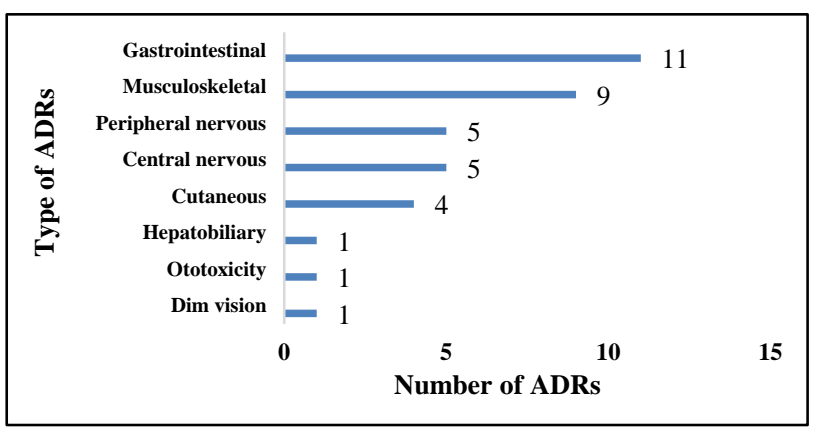

Figure 1: Types of ADRs seen with ATT.

Table 3: Antitubercular drugs causing ADRs.

\begin{tabular}{|ll|}
\hline Anti-tubercular drugs & Number of ADRs (\%) \\
\hline Isoniazid & $4(10.8)$ \\
\hline Rifampicin & $21(56.75)$ \\
\hline Pyrazinamide & $9(24.32)$ \\
\hline Ethambutol & $1(2.7)$ \\
\hline Streptomycin & $1(2.7)$ \\
\hline Kanamycin & $1(2.7)$ \\
\hline
\end{tabular}

\section{DISCUSSION}

Out of 37 patients who experienced ADRs, 22 (59.45\%) were male and $15(40.54 \%)$ were female. A study by Yee et al considered female gender as a risk factor for the occurrence of ADRs due to their smaller body size and body weight compared to males. ${ }^{10}$ However, our study did not establish any association between gender and incidence of ADRs.

In present study higher ADRs were seen in middle age group from 36 to 45 years. Similar findings were reported in study by Priyadarshini et al. ${ }^{11} 36$ out of 37 patients were diagnosed with pulmonary TB. The finding was consistent with other study. ${ }^{11}$

Maximum number of ADRs reported in our study were gastrointestinal ADRs 11 (29.72\%) like nausea, vomiting and pain abdomen which was similar with study by Dhingra et al. ${ }^{12}$ Rifampicin was the most prevalent drug responsible for these GI symptoms. This was followed by musculoskeletal ADRs 9 (24.32\%) which included joint pain and hyperuricemia. Pyrazinamide was the most common drug responsible for joint pain. Priyadarshini BG et al also reported gastrointestinal as most common ADR followed by others like rash and peripheral neuropathy in their study. ${ }^{11}$ But in contrast to our findings, Manish R et al reported that hepatobiliary was the most common ADRs in their study. ${ }^{13}$
Other ADRs reported were central and peripheral sensory that included giddiness, vertigo, tingling and numbness (peripheral neuropathy). Isoniazid was responsible for most of these ADRs. And also, one case of hepatitis with raised serum enzyme levels was seen due to INH. Kanamycin was responsible for ototoxicity and Ethambutol caused decreased vision in one case each.

On evaluation of causality majority of ADRs were probable $51.35 \%$ followed by possible $48.65 \%$. similar findings were seen in study by Gholami K et al. ${ }^{14}$ Severity assessment showed $64.8 \%$ reactions were of mild nature, $27.02 \%$ moderate and $8.1 \%$ as severe. A study by Tak DK also supported this result. ${ }^{15}$ Outcome assessment showed $70.3 \%$ patients were recovering, $24.32 \%$ had recovered from reactions and $5.4 \%$ did not recover as they were suffering from ototoxicity which lead to hearing loss and decreased vision.

\section{CONCLUSION}

There is a need for proper monitoring for ADRs due to antitubercular drugs. Prevention of ADRs reduces patient's burden of increased hospital stay and expense occurring due to it. Counselling of patients regarding adherence to ATT is important to prevent drug resistance and they must be educated to report the reactions for further prevention and management of ADRs.

\section{Limitations}

Dechallenge and rechallenge tests could not be done as it was a retrospective observational study. Sample size was small in our study, hence further prospective studies can be done to assess more ADRs related to antitubercular drugs.

\section{ACKNOWLEDGEMENTS}

Authors would like to thank their director and head of the Department of Pharmacology and staff of the institution for their support.

\section{Funding: No funding sources}

Conflict of interest: None declared

Ethical approval: The study was approved by the Institutional Ethics Committee

\section{REFERENCES}

1. Maartens G, Wilkinson RJ. Tuberculosis. Lancet. 2007;370(9604):2030-43.

2. Fauci G, Braunwald K, Hauser L. Tuberculosis. In Harrison's Principle's of Internal Medicine, $17^{\text {th }}$ edition. USA: The McGraw Hill Companies. 2008:970.

3. Sagbakken M, Frich JC, Bjune G. Barriers and enablers in management of tuberculosis treatment in Addis Ababa, Ethiopia, a qualitative study. Bmc Public Health. 2008;8(11):55-9. 
4. Tripathi KD. In: Adverse drug effects. Essentials of medical pharmacology. 7th ed. New Delhi: Jaypee Brothers. 2015: 82-91.

5. Abideen SP, Chandrasekaran K, Maheswaran U, Vijayakumar A, Kalaiselvan V, Mishra A, et al. Implementation of self-reporting pharmacovigilance in anti-tubercular therapy using knowledge based approach. J Pharmacovigilance. 2013;1:101.

6. Singh A, Prasad R, Balasubramanian V, Gupta N, Gupta P. Prevalence of adverse drug reaction with first line drugs among patients treated for pulmonary tuberculosis. Clin Epidemiol Global Health. 2015;3:80-90.

7. Mathew S, Joseph A. Adverse effects of antituberculosis drugs in patients under dots category1. J Evid Based Med Healthc. 2017;4(8):415-22.

8. Helling $\mathrm{M}$, Venulet J. Drug recording and classification by the WHO research centre for international monitoring of adverse reactions to drugs. Methods Inform Med. 1974;13(3):169-78.

9. Hartwig SC, Siegel J, Schneider PJ. Preventability and severity assessment in reporting adverse drug reactions. Am J Hosp Pharm. 1992;49:2229-32.

10. Yee D, Valiquette C, Pelletier M, Parisien I, Rocher I, Menzies D. Incidence of serious side effects from first- Line antitiberculosis drugs among patients treated for active tuberculosis. Am J Respir Crit Care Med. 2003;167:1472-7.
11. Priyadarshini BG, Ravikumar P, Umme S. A study of adverse drug reactions among pulmonary tuberculosis patients treated under dots in a tertiary care hospital. Int $\mathbf{J}$ Basic Clin Pharmacol. 2017;6(4):779-83.

12. Dhingra VK, Rajpal S, Aggarwal N, Aggarwal JK, Shadab K, Jain SK. Adverse drug reactions observed during DOTS. J Commun Dis. 2004;36:251-9.

13. Shrivastava MR, Singh GP, Kumar D, Pathak KS, Sah D, Chowdhary KA, et al. Adverse drug reactions due to anti tubercular drugs during the initial phase of therapy in hospitalised patients for tuberculosis in Sri Krishna Medical College, Muzaffarpur, Bihar. J Evid Based Med Healthc. 2017;4(18):1031-6.

14. Gholami K, Kamali E, Hajiabdolbagh Mi, Shalviri G. Evaluation of antituberculosis induced adverse reactions in hospitalized patients. Pharm Practice. 2006;4:134-8.

15. Tak DK, Acharya LD, Gowrinath K, Rao PGM, Subish P. Safety evaluation of antitubercular therapy under revised national tuberculosis control programme of India. J Clin Diag Res. 2009;3:1395401.

Cite this article as: Mogali SM, Ratnakar JS, Kotinatot BC. Study of adverse drug reactions among tuberculosis patients in a tertiary care hospital: a retrospective observational study. Int $\mathbf{J}$ Basic Clin Pharmacol 2020;9:768-71. 